\title{
Hegel, la recepción de su concepto de religión en diversos autores
}

Diego Fernando Correa Castañeda

Universidad Nacional de Educación

a Distancia-UNED, España

(c) $\underset{\mathrm{Br}}{\mathrm{i}}$ 


\title{
Hegel, la recepción de su concepto de religión en diversos autores
}

Resumen: hacer un recorrido por las diferentes recepciones del concepto de la religión de Hegel, especialmente el estudio llevado a cabo por Manuel Valls, las diversas críticas realizadas por: Lukács, Garaudy, Marx entre otros. En primer lugar, se verá en detalle cuáles fueron los presupuestos que Ilevaron a Hegel a subordinar la filosofía a la religión; en segundo lugar, se tratarán de encontrar los vínculos entre la religión y la política; por último, también es importante hacer un breve comentario sobre la disputa que se originó entre los hegelianos de derecha, o sea, los viejos hegelianos y los hegelianos de izquierda.

Palabras clave: Filosofía de la religión, religión y política, hegelianos de izquierda y de derecha.

\section{Hegel, the reception of his religion concept in several authors}

\begin{abstract}
: take a tour on the different aspects surrounding the figure and the philosophy of Hegel's religion: In the first place, it'll be seen in detail which where the Budget that carried Hegel to subordinate the philosophy to the religion; at second place, it'll be treated to find the connection between religion and politics; and in the last place, it's important to make a short commentary about what was originated between right wing hegelians, I mean, the old hegelians and the left wing hegelians.
\end{abstract}

Keywords: Religion's philosophy, Religion and politics and left wing/right wing hegelians.

Fecha de recepción: 12 de diciembre de 2016

Fecha de aceptación: 6 de mayo de 2017

Forma de citar (APA): Correa Castañeda, D. (2017). Hegel, la recepción de su concepto de religión en diversos autores.

Revista Filosofía UIS, 16(2), doi: http://dx.doi.org/10.18273/revfil.v16n2-2017003

Forma de citar (Harvard): Correa Castañeda, D. (2017). Hegel, la recepción de su concepto de religión en diversos autores. Revista Filosofía UIS, 16(2), 75-94.

Diego Fernando Correa Castañeda: colombiano. Doctorando en filosofía. Magíster en filosofía teórica y práctica. Universidad Nacional de Educación a Distancia (UNED), España.

Correo electrónico: dcorrea9@alumno.uned.es

\footnotetext{
*Revisión de tema.
} 


\section{Hegel, la recepción de su concepto de religión en diversos autores}

\section{Introducción}

El artículo consistirá en hacer un recorrido por los diferentes puntos de vista en torno al concepto de religión en Hegel, los cuales vienen derivados de las nociones de diversos comentaristas en torno a dicho concepto. Para ello, me serviré de diferentes fuentes, dentro de ellas las más destacadas son el estudio realizado por Manuel Valls, integrado en el libro "Filosofía de la religión", editado por Manuel Fraijó; también formarán parte los aportes realizados por Georg Lukács, Roger Garaudy y Karl Marx, entre otros. Siempre hablando de Hegel a través de sus comentaristas trataremos de ver en detalle cuáles fueron las diferentes recepciones del concepto de religión en ellos y la diversidad y riqueza de dicha recepción. Dentro de esa asimilación lo más destacado sería el asunto que habla de la subordinación de la filosofía a la religión. En segundo lugar, se tratarán de encontrar los vínculos entre la religión y la política. Por último, también es importante hacer un breve comentario sobre la disputa que se originó entre los hegelianos de derecha, o sea, los viejos hegelianos y los hegelianos de izquierda, esto es, los jóvenes hegelianos, entre los que se encontraban Feuerbach y Marx.

Además de esto se harán otros tipos de análisis relacionados directamente con la misma problemática y que básicamente consistirán en la confrontación que se originó en el ámbito filosófico debido a la herencia dejada por Hegel, que como dice Francisco José Martínez, consiste en las grietas que aparecieron alrededor del redondo Absoluto, ese que Hegel creyó cerrado y que después de su muerte comenzó a dejar escapar sus contenidos, no para que fueran borrados, sino simplemente para en unos casos ser mejorados y en otros invertidos o superados, como fue el caso del marxismo. 


\section{Relación entre religión y filosofía}

Para poder dar comienzo al debate que se generó en torno a cuál debería ser la disciplina que rigiera los destinos de la humanidad, si la religión o la filosofía, tenemos que detenernos en la confrontación que según Hegel se da entre ambas. Hegel da comienzo al debate asignándole a cada una de ellas un papel específico - no olvidemos que, para él, la primacía siempre será para la filosofía, el darle un papel más relevante a la religión es más bien un acto de estrategia contra la razón ilustrada - en dicha asignación de tareas, la filosofía es la encargada de unificar el conocimiento en el redondo Absoluto a través del concepto.

Hegel divide su sistema en tres partes, siendo cada una de ellas productos del ser humano; es así como de forma ascendente crea una jerarquización, la cual deja muy bien explicada Lukács en sus "Aportaciones a la historia de la Estética", en ella dice el gran filósofo húngaro que, la estética hegeliana, como modelo similar al resto de su obra, no es más que una sección del gran desarrollo histórico del mundo, que va desde la naturaleza hasta el espíritu absoluto. "En este desarrollo la estética es el grado inferior de manifestación del "Espíritu absoluto", a saber, el grado de la intuición. El grado inmediatamente superior es el de la representación, o sea, la religión; y el nivel supremo es el del concepto, el de la filosofía" (Lukács, 1966, p. 134). Este esquema se trae a colación para ver el lugar que le asigna Hegel tanto a la religión como a la filosofía dentro de su sistema. Una vez visto el lugar que ocupan podremos pasar a ver la disputa que se da entre las dos, disputa que consiste en que ambas tienden al mismo objetivo, que no es más que el conocimiento de la verdad, esto es, de Dios, pero a través de diferentes medios.

Como se puede muy bien suponer "un bien compartido por varios propietarios se convierte siempre en objeto de disputa" (Fraijó, 2010, p. 208); es así como en la mutua búsqueda de la verdad ambas disciplinas se enfrentan en lo referente a los medios utilizados. Para que quede claro desde el principio, la religión utiliza la representación y la filosofía el concepto; lo que ocurre es que para Hegel la representación se queda en la mera apariencia y no es capaz de penetrar en las cosas, para decirlo con las palabras que utiliza Lukács en su obra "El Joven Hegel": "La religión es la objetividad sin objeto" (Lukács, 1964, p. 232); aunque parece obvio expresar lo mismo sobre la filosofía, ya que ambas al fin y al cabo pretenden ser objetivas sin tener objeto, esto es, tratan de imponer su visión de la realidad, pero siempre dentro del inestable mundo de lo suprasensible o transcendental. Es en este sentido que hay que entender la aportación que hace Lukács. Hegel se da perfectamente cuenta de ese problema de la representación religiosa. Mientras que el concepto filosófico del Absoluto es capaz de contener dentro de sí a la totalidad, o al menos eso es lo que él se propone hacer. 
Debido a la importancia de la confrontación y al lugar privilegiado que ocupa en el pensamiento de Hegel trataremos de ver cómo el gran sistema hegeliano rechaza a la razón ilustrada por dos motivos principales. El primero y más importante es la deslegitimación a la que la razón quiere someter a la religión. El segundo es la pretensión ilustrada de querer racionalizar todos los ámbitos humanos. Vayamos con el primero de los motivos: dicha deslegitimación se debe al positivismo en el que se ha convertido el hecho religioso, ya que así, lo que han conseguido los fundadores de la iglesia ha sido blindar a la religión para protegerla de los posibles ataques que ésta iba a recibir por parte del conocimiento humano, eso que normalmente llamamos la razón, siendo este el principal motivo que llevó a los filósofos ilustrados a atacar la religión, pero no el único. Pensemos por ejemplo, en el hecho de que la religión era el gran soporte en el que estaba asentada la legitimidad del antiguo régimen, o en cualquier caso, si no era el antiguo, al menos era el que se proponían derrocar, con lo que en el fondo, al atacar a la religión, estaban era en verdad atacando a una de las principales instituciones que legalizaban la tiranía del sistema monárquico, sistema asentado en el derecho divino, al cual estaban adheridas todas las monarquías de la época -no se puede pasar por alto que uno de los mayores debates de la época era que los reyes estaban sujetos a la justicia divina, lo que a la larga los separaba del resto de los seres humanos-. Este hecho fue el detonante principal del rechazo mostrado por la nueva y floreciente disciplina — la razón ilustrada - ante la religión. Para aquella era inadmisible mantener el privilegio ante una institución que, basada en meros supuestos metafísicos, se proponía o respaldaba mantener en el poder a las viejas formas que aplastaban el progreso del resto de los mortales. Todo esto dentro del ambiente en el que la floreciente burguesía estaba llamada a reemplazar al ya moribundo sistema feudal. Es en este sentido que se puede entender el auge de la racionalidad ilustrada, la que llevada de la mano de "esa burguesía ascendente se proponía dirigir una batalla política contra la religión tradicional" (Garaudy, 1985, p. 9).

Ésta disputa extiende sus tentáculos mucho más allá. La religión pre-ilustrada era totalmente consciente de que la separación entre religión positiva y especulativa era con el propósito de que la verdad revelada directamente por Dios no pudiera recibir ningún reproche por parte de la actividad especulativa del hombre. Los filósofos ilustrados, de los cuales Hegel es un heredero, tildaban dicha posición de "simplemente irracional y contrario a la libertad de pensamiento" (Fraijó, 2010, p. 213). Según Ramón Valls:

La primera postura de Hegel al respecto es todavía la de un seguidor de la Ilustración: Jesús enseñó una religión racional, pero ésta se convirtió en positiva, es decir, en contraria a la razón y libertad, cuando los cristianos se organizaron como iglesia y se aliaron con el Estado. Aunque más tarde Hegel variará sustancialmente su visión y valoración de la positividad de las religiones, defenderá siempre, desde este momento hasta el fin de su vida, la separación de las Iglesias y el Estado (Fraijó, 2010, p. 213). 
Hegel se opone en parte a los ataques que se le lanzan y, en sentido contrario, afirma la gran importancia de la religión, importancia que nosotros debemos tomar en el mismo sentido en el que él la coloca, ya que es la que más se ha acercado al Absoluto que él pronto propondrá como síntesis de su sistema, absoluto que él ve contenido en la religión en general y en el cristianismo en particular. Para Hegel el descubrimiento de la naturaleza se lo debemos al logos griego, mientras que el del espíritu se lo debemos al cristianismo. Además de esto, y siempre en aras de la claridad, es oportuno hacer algunos aportes en torno a eso que Félix Duque llama: Redondo Absoluto. Para ello me remito a las palabras expresadas en la introducción de "El Concepto de Religión" de Hegel, realizado por Arsenio Guinzo.

En la filosofía de la religión de Hegel, no hay propiamente hablando, dualismo. Toda la filosofía de Hegel gira tenazmente acerca de este punto: no hay dos razones o dos espíritus. No hay una razón divina y una razón humana que operen cada una por su lado. La razón es tan solo una. La razón del hombre es lo que hay de divino en el hombre, a la vez que el espíritu de Dios no es un espíritu que esté más allá de las estrellas como algo extra mundano (1981, p. 9).

Esta cita refleja fielmente la posición hegeliana ante la división que hace la religión a través de la representación y, ante la cual, él toma una posición de rechazo, no olvidemos que el único que está en condiciones de unificar a los hombres es el concepto filosófico. Y tampoco debemos olvidar que ha sido Lukács quien mejor ha sabido ver que el espíritu no habita en un más allá, sino en un más acá. Estas nociones se desarrollarán más adelante.

Si el primer motivo era la deslegitimación a la que la razón ilustrada quería llevar a la religión, el segundo motivo y, no menos importante, es su afán de querer reducirlo todo a la racionalización; dicho proceso ilustrado trae consigo algo que Hegel rechaza de plano: consistente en la consecuencia o resultado fruto de querer racionalizar a la propia religión, ya que al hacerlo, la poderosa razón ilustrada termina afirmando los dos conocidos postulados prácticos introducidos por Kant: la inmortalidad del alma y la existencia de Dios. Es como si necesitáramos saber que nuestra alma es inmortal para que nos dé tiempo de llevar a cabo la labor encomendada y conseguir la tan ansiada libertad, y necesitáramos afirmar la existencia de Dios para poder alcanzar la felicidad soñada. Hegel ve ambos propósitos innecesarios, es más, los ve insuficientes, ya que no logran "motivar el comportamiento hermanado de los individuos y los pueblos" (Fraijó, 2010, p. 210), labor principal encomendada a la religión.

Más adelante se ampliarán las relaciones que se establecen entre la religión y la política para poder aquélla paliar las deficiencias a la que se vio abocada una vez la razón ilustrada impuso su poder; al formar la religión una alianza con el Estado, ha entrado en la esfera positiva, este comportamiento es atacado y 
rechazado por Hegel. Como se puede ver, los motivos por los que se afronta el hecho religioso son múltiples; uno de los rasgos más característico de este debate es el hecho de que lo que por un lado se quiere rechazar por sus vínculos inadecuados, por el otro se quiere resaltar por su gran capacidad unificadora y dadora de sentido, esto, claro está, recordando el papel que ha tenido la religión como descubridora de lo espiritual. De ahí que Hegel tiene ante sí dos aspectos de un mismo problema a los que tratará de dar solución.

En este conflictivo proceso que se está desarrollando no podemos perder de vista otros aspectos que, aunque vienen a ampliar lo dicho hasta ahora, no podemos dejar de lado. Simplificando: se ha dicho que Hegel, en primer lugar, le da la primacía a la filosofía, eso para él es un hecho evidente; también se ha dicho que invierte dicho proceso para salvar en parte a la religión de los ataques que ésta recibe por parte de la razón ilustrada, ya que ésta se excede en sus ataques y menosprecia ese enorme poder que solo ella ha tenido al ser capaz de descubrir el espíritu —ya que el conocimiento de la naturaleza lo consiguieron los griegos a través del logos- A Ahora bien, es momento de dejar otros aspectos del problema resueltos. Hegel es totalmente consciente del lugar que ocupa la religión en la época en la que le tocó vivir, es así como nos lo recuerda Lukács:

Gran parte de la filosofía hegeliana se desarrolla bajo el signo de la victoria de la llustración sobre la religión. Paso a paso es expulsada la religión de las posiciones que ocupó durante milenios, y la dialéctica del movimiento inmanente de los objetos terrenos, del hombre y de sus relaciones sociales, de la consciencia humana y de las cosas sobre las cuales se despliega la práctica humana, ocupa todos los terrenos de la ideología que antes estaban Ilenos de contenidos religiosos (1964, p. 482).

Solo tenemos que detenernos un momento en dicho período. Situémonos en el tiempo. Estamos en plena revolución francesa, o, mejor dicho, en el momento en el que Francia tiene bajo su dominio a toda Europa bajo la figura de Napoleón, todos sabemos la gran influencia que recibió Hegel de dicho acontecimiento. Basta recordar el famoso — aunque sospechoso_ ( para Manuel Jiménez Redondo simplemente es inverosímil por la falta de tiempo) episodio que narra el momento en que Hegel "con el manuscrito de la Fenomenología bajo el brazo, sale al encuentro del nuevo espíritu que va montado a caballo... [Napoleón]" (Hegel, 2006, p. 42). Episodios como este son los que están marcando los nuevos tiempos en los que el suelo alemán devino uno de los campos de batalla en donde se jugaba la historia del mundo entre las fuerzas del pasado y las del porvenir: "La Revolución Francesa y el Imperio napoleónico en gigantesco torbellino atraen y trasforman a los pueblos, sus instituciones, sus hombres y sus ideologías" (Garaudy, 1973 , p. 10). Es una época convulsa de la que Hegel formaba parte y en la que además se vio forzado a participar. Tenemos que recordar la anécdota que lo ubica en el jardín de la Universidad de Tubinga "bailando alrededor del árbol de 
la libertad" (Fraijó, 2010, p. 212), (Reale y Antiseri, 2010, p. 99), acompañado por sus dos mejores amigos y compañeros de estudio, Schelling y Hölderlin. Aun dentro de este ambiente convulso y cambiante, en Hegel la religión siempre estaba presente, como queda de manifiesto en una carta suya enviada a Schelling: "Razón y libertad sigan siendo la consigna, y nuestro punto de unión la Iglesia invisible" (Hegel, 2003, p. 56).

Antes de dar paso a las implicaciones que desembocaron en el romanticismo es absolutamente necesario hablar de otros aspectos en lo referente a la relación de Hegel con la ilustración y la religión. Todos sabemos que el acontecimiento que más dejó marcado a Hegel fue la Revolución Francesa, no hace falta hablar de ello en detalle, son suficientemente conocidos. Pues bien, lo que Hegel más admira de dicha revolución es la fuerza con la que la humanidad va a tomar un nuevo rumbo, eso está muy claro en él; pero entonces icuál es el problema? Pues nada más y nada menos que lo que él ve muy bien en Francia, no lo ve bien para Alemania. Esta es quizás una de las más llamativas recepciones del pensamiento hegeliano, esta vez asimilado y expuesto por Garaudy, quien ve en estas nociones la mayor contradicción de la filosofía hegeliana. Ya que lo que la Revolución Francesa consiguió en Francia, lo había conseguido Alemania con la reforma, o sea, en Francia se quita el poder que la religión tenía sobre los aspectos sociales, poder utilizado, podría decirse, como ley; mientras que en Alemania ese paso ya se había dado, llevar a la religión a ese estado primitivo de pureza, esto es, volver a su génesis, esa en la que aún no había intervenido la política. Pero entonces ¿qué quería justificar Hegel realmente?: "de allí se desprende la contradicción principal de la obra de Hegel: una exaltación teórica de la Revolución Francesa, que en la práctica se transforma en una justificación de la monarquía prusiana" (Garaudy, 1985, p. 11). Para Garaudy Hegel se halla en una situación muy paradójica "demostrar la necesidad histórica de revolución en Francia y negar su posibilidad en Alemania" (11). Esto sí que es sorprendente. Claro, para Hegel el fin de la historia está contenida en la forma de gobierno prusiano, esa misma a la que Francis Fukuyama en su obra "El fin de la historia" propone volver, o, mejor dicho, en la constitución de un Estado poderoso que sea capaz de garantizar todos los derechos y en el que no debe estar la religión; Hegel rechaza de plano la unión entre ambas esferas. Pero sí resulta muy llamativo que lo que respalda y eleva su ánimo y que es visto como el acontecimiento que marcará el futuro, sin embargo, lo rechaza para su propia nación. No es de extrañar que en el fondo esté protegiendo la forma de gobierno en la que vive y que a lo mejor es la que le da de comer. Existen en la historia muchos episodios similares, en los que los grandes pensadores tienen que acogerse a los designios políticos de sus respectivos países si quieren continuar con su labor, en este caso académica. No está exento en esto ni el propio Lukács, el cual tuvo que claudicar ante al gran poder del partido comunista, por no decir del propio Stalin. 


\section{Romanticismo}

Sería igualmente importante no perder de vista el otro acontecimiento que se estaba desarrollando en aquélla misma época y en el que Hegel iba a jugar un papel central: el Romanticismo, con el que se quiere nuevamente recuperar el equilibrio clásico ya antes llevado a cabo por el renacimiento. El hombre se da cuenta de que eso ya no es posible, el hombre ha perdido la inocencia, descubre que puede ser dueño de su destino, como arma lleva el estandarte de la razón, pero se enfrenta con la dolorosa realidad de que el mundo ya no es fabulable. Hölderlin en "Hiperión" lo deja claramente formulado: "ya no somos los mismos, los hombres de hoy son muy distintos de los antiguos" (Reale y Antiseri, 2010, p. 49). En este ambiente es en el que se desarrolla la filosofía hegeliana, el producto de toda esta amalgama de circunstancias es el anteriormente citado romanticismo, cuyo eje central gira en torno a querer volver a instaurar la cultura clásica en suelo europeo y descubrir que ya no es posible. Esta situación de ocupación por parte de los franceses y de querer volver a la antigua grandeza es en el que se da uno de los mayores florecimientos del pensamiento humano. No olvidemos que, en un período de tiempo relativamente corto, se suceden los más grandes pensamientos que el género humano ha dado, todos son suficientemente conocidos, no hace falta hacer una lista detallada.

Si ya no es posible vernos en el espejo griego, entonces vamos a crear a partir de nosotros mismos, los modelos ya no serán los grandes mitos clásicos, a partir de ahora seremos nosotros los constructores de nuestra propia realidad. Aquí Hegel tiene el enfrentamiento con la parte de la ilustración que pretende, entre otras cosas, deslegitimar a la religión a través de métodos que él considera poco apropiados, ya que la razón pretende deshacerse con simples artimañas de la única disciplina qua ha sabido aglutinar en torno a una sola idea todo el sentimiento humano, de ahí que se estén haciendo constantes referencias sobre los motivos de dicha disputa.

\section{Absoluto, distinción con la representación}

Ahora bien, la lucha se debe a la insuficiencia que detecta Hegel en la forma en que la religión trata su ámbito de estudio, esto es, la realidad divina. Para él, el medio de conocer a través de la representación se queda corto debido a que separa la realidad a conocer y el sujeto del conocimiento, o lo que viene a ser lo mismo, es la separación entre sujeto y objeto. Valls cita a Hegel: "la religión contempla sus objetos como algo enfrentado al sujeto que los conoce y separados de él" (Valls citado en Fraijó, 2010, p. 230). Esto es lo mismo que decir que tanto Dios como las cosas estás de un lado y del otro lado estamos nosotros. Aquí el punto capital es que esto va en contra del Absoluto propuesto por Hegel, en el que supuestamente dicha división no se da. Para que esta noción 
nuclear del pensamiento del creador de la dialéctica nos quede más clara vamos a buscar apoyo: "La filosofía de Hegel es una filosofía de lo Absoluto, y aunque este Absoluto es para Hegel esencialmente resultado, siendo Absoluto tiene que hallarse, asimismo, al comienzo, dado que no puede derivarse de nada distinto de él" (Hegel, 1981, p. 8).

Como se puede ver, es el mismo "Uno" de Plotino, del que no escapa nada, ya que está en todas partes, no es arriesgado si hablamos de Panteísmo. O para que quede mejor expresado, es el mismo "ex nihilo", el cual existe desde el principio. Al no haber surgido nada de él y, a su vez, él no producir nada, entonces nos encontramos con un principio que está en todas partes, tanto al principio como al fin. Hegel pretende decirnos que la religión tiene el mismo sentido que el Absoluto, o sea, si ella aparece al final de toda la reflexión filosófica, inevitablemente también tiene que aparecer al inicio, ya que tanto del Absoluto como de la religión no escapa nada, ya se dijo anteriormente, es ese llamado "en kai pan" el Uno y Todo. Ese es el que, según Valls (Valls ctd en Fraijó, 2010, p. 215), Hegel pretende dinamizar. A partir de ahora Hegel va a definir el Absoluto con una fórmula que no abandonará jamás «Sustancia-sujeto». Con ésta alcanza Hegel la madurez de su sistema.

\section{El absoluto y Oriente}

Nos estábamos refiriendo al Absoluto; ahora vamos a echar un vistazo a la no dualidad del sujeto y el objeto. Resulta igualmente llamativa la aparente gran dosis de orientalismo que parece tener el concepto de Absoluto en Hegel; es oportuno mencionarlo para que nos demos cuenta de la amplitud de dicha noción. La historia nos enseña que el hombre siempre ha estado buscando un principio —una filosofía primera o, quizás, un primer motor inmóvil, como lo solía llamar en su Física Aristóteles - que impida entre otras cosas tener que someternos a un regreso infinito (Solís, 2009). En este sentido es en el que se da la similitud entre el Absoluto hegeliano y el Absoluto hindú. Ambas disciplinas pliegan el mundo natural y humano a un solo principio, esto es, niegan en el fondo cualquier tipo de dualidad. Aun teniendo una gran similitud sus respectivos principios fueron aplicados de forma diferente. Valga también decir a este respecto que resulta sumamente llamativa la similitud entre ambas maneras de ver la realidad, y más, cuando se queda flotando el aire la aparente influencia oriental en occidente. Hay que recordar que para Hegel la filosofía comenzó verdaderamente en Grecia, negando cualquier tipo de procedencia de carácter oriental. A este respecto se refiere la orientalista María Teresa Román en su obra Sabidurías Orientales de la Antigüedad, cuando dice al respecto: 


\begin{abstract}
Uno de los filósofos occidentales que más ha contribuido a extender la idea de que en la India no ha habido filosofía, o que la filosofía es una creación, un descubrimiento original propio solo de Occidente y que nació en Grecia, ha sido el prestigioso filósofo alemán Georg Wilhelm Friedrich Hegel. Éste desterró al pensamiento chino e indio de los capítulos importantes de su obra (2008, p. 35).
\end{abstract}

Según Hegel, la filosofía apareció en la Grecia clásica. La aparente analogía se presta a engaño, ya que si los orientales buscan a través de la no dualidad —el absoluto- escapar de la rueda dhármica y dolorosa de las reencarnaciones, con lo que en el fondo están es huyendo del mundo. Hegel por el contrario afirma que el Absoluto hay que vivirlo, es más, para él, vivir es precisamente pasar por todos los niveles que la realidad nos va presentando. En este sentido la analogía es por lo menos curiosa y más si sumamos el hecho antes mencionado de que, para Hegel, la filosofía da comienzo es precisamente en Grecia, allí según él, se da la confluencia entre el pensamiento y la sociedad o, en donde la especulación forma parte integrante del debate público, cosa que al parecer no se da en oriente, ya que la meditación es más un hecho privado. Este hecho es más importante de lo que parece a primera vista, ya que guarda mucha relación con el efecto que se produce cuando los valores religiosos son introducidos de manera laica en la sociedad, provocando así que la religión en parte sea absorbida o tienda a desaparecer. Estos aspectos serán desarrollados más adelante.

Para Hegel la cumbre de la revelación es el cristianismo. "El credo cristiano sirve y es, él mismo, compendio de todas las religiones" (Valls citado en Fraijó, 2010, p. 215), pero sin embargo "no alcanza a superar el modo de representación de conocimiento" (Fraijó, 2010, p. 211). Aquí lo más importante es el medio del que se sirve la religión para darse a conocer y también a través del que se conoce a sí misma: el arte, como medio por antonomasia utilizado por la religión para representar sus contenidos, creando de esta manera otra realidad paralela separada de nosotros y, además, de la misma imagen que quiere dar a conocer: Dios - Lukács ataca de plano estos presupuestos - Desde luego todo esto hay que entenderlo en el sentido antes mencionado de que la religión no tiene objeto «es la objetividad sin objeto» de ahí que se objetive a través del arte. Así surge la dicotomía entre los tres agentes en cuestión: por un lado estamos nosotros como la parte destinada a recibir la información que se nos quiere dar, el siguiente elemento es la imagen religiosa representada, o sea, la figura de cualquier alegoría divina; como tercer elemento en escena está la misma figura divina en sí, ya que no es lo mismo la obra artística como tal y lo que ella representa, de ahí la acusación hegeliana de que la representación religiosa divide los elementos, separándolos en compartimientos estancos y, alejándose del unificador concepto filosófico, único capaz de realizar dicha unión. Cosa diferente ocurre con la filosofía, la cual no utiliza la representación sino el concepto. Esta es la gran diferencia que denuncia Hegel y que se propone aclarar, dejando a la religión en un puesto secundario, así sea de momento. 


\section{Religión y política}

Ahora bien, vamos a entrar en un terreno más complejo e importante, se trata de la relación que existe entre la religión y la política; este hecho es tan vital para comprender a Hegel que el gran filósofo francés Roger Garaudy basa en él el centro de su investigación: "el problema inicial de Hegel es indivisiblemente político y religioso" (Garaudy, 1985, p. 10). Para poder dejar las cosas en su lugar es necesario continuar al pie sus reflexiones, según Garaudy, para Hegel: "Fue un error capital de su época haber separado los dos aspectos de un mismo problema... [Ya que él buscaba precisamente era unirlos en uno solo] concebir el Estado como una fuerza exterior a los miembros que lo componen, y concebir la religión como elemento subjetivo individual" (Garaudy, 1985, p. 10).

Ya antes se hizo alusión a ello, pero ahora es momento de verlo más en detalle. Para Hegel lo más importante es encontrar un medio de unificación a través del cual el hombre llegue a la comprensión total de la realidad, en dicha lucha se encuentran en contienda la religión y la filosofía. La religión es incapaz de unificar el sentimiento humano en una sola forma y, por eso, se ve en la necesidad de acudir a la política; en este hecho ve Hegel la unión de la religión con la tiranía. El gran genio de Hegel lo llevó a descubrir cosas que nunca habían sido vistas de esta manera, solo basta con mirar la situación de nuestro mundo actual para ver lo frescas que están las reflexiones del gran filósofo alemán.

Tendríamos que preguntarnos qué pensaría él sobre la situación en la que la religión busca aliarse con la política, pero no para "motivar el comportamiento hermanado de los pueblos" (Fraijó, 2010, p. 212), sino para no solo no desaparecer, sino para no perder poder sobre el mismo, esto es, sobre el pueblo, porque en eso se ha convertido la religión, en un agente de dominio político; la iglesia ahora busca alianzas con la política, pero es para que la política le ayude a no entrar en declive, ve en ella una boya salvavidas de la que la política se ha sabido servir, con lo que la colaboración es mutua y, a su vez, la política se sirve de la religión para ganar adeptos. Si antes decía Hegel: que por falta de un imperativo general la alianza era necesaria, ahora dicha alianza sigue siendo necesaria, pero el objetivo ha cambiado. Es evidente que las motivaciones han evolucionado, antes era con unos propósitos más aceptables; hay que entender que se buscaba era una especie de consenso general, el cual es legítimo, máxime si se iba detrás de una noción o de una especie de universal cultural que amalgamara dentro de sí los sentimientos de toda la humanidad. Para no repetir lo dicho anteriormente, es un hecho sumamente llamativo el que Hegel rechace los cambios producidos por la Revolución Francesa, que se niegue a que sean introducidos en Alemania para poder dejar que el Estado absolutista prusiano se consolide como única forma posible de gobernar. 
Yendo un poco más allá vamos a tratar de ver otro aspecto del problema. Esta vez se trata de la forma en la que percibimos el hecho religioso. Hegel atina y capta la esencia de la religión en general y del cristianismo en particular y, además, expresa su destino; debemos nuevamente prestar atención a Hegel, ya que su aguda visión nos vuelve a poner en la senda de ver el hecho religioso con mucho rigor. Según Garaudy:

El destino de la religión es en primer lugar terminal en el seno de la cultura, ya que ésta ha digerido y asimilado bajo formas seculares los viejos valores cristianos, de ahí que la religión se vuelva superflua como institución, esto tiene una consecuencia nefasta para la religión y es que la cultura la empuja hacia lo privado. Ya no existe la comunidad humana. Cada uno se repliega en su egoísta propiedad privada o en un estéril sueño interior (1985, p. 19).

De ahora en adelante la religión solo tendrá cabida en el ámbito privado del individuo, como entre otras cosas tiene que suceder en un mundo que está basado en el triunfo económico individual (Weber). Ya que en el público solo tendrá la responsabilidad de la educación. En el fondo Hegel estaba también haciendo unas valoraciones demasiado generosas para la religión, porque privarla de ser la dadora de sentido, en sintonía con la sociología francesa de Durkheim, y darle a cambio el poder sobre la educación es en el fondo dotarla de unos poderes que nada tienen que envidiar a su antigua función.

De todas maneras, alegrémonos de que estemos siendo testigos de los últimos coletazos de la contienda, ya que la situación actual no da más de sí. Es decir, siguiendo a Hegel, la cultura empuja la religión hacia el rincón de lo privado y cada vez ese efecto se vuelve más notable, por no decir más dramático, porque en el fondo, el que la religión desaparezca de la vida pública y se interne en lo privado no deja de ser un problema.

La especialización de la ciencia produce que el sentido global de la vida y la realidad no se puede obtener ya de ella y el deterioro y abandono de las concepciones religiosas en el mundo moderno desprovee de valores a dicho mundo. El sentido, siempre limitado y precario, queda reducido al ámbito de la vida privada y de las relaciones inmediatas de los individuos entre sí (Martínez, 2011, p. 290).

De estas nociones surgieron las mayores críticas al marxismo, al querer desprenderse de la religión de un solo golpe. Eso se podría hacer si ya tienes una noción preparada que sustituya a la anterior. Siguiendo a Espinoza "Un afecto no puede ser reprimido ni suprimido sino por medio de otro afecto contrario, y más fuerte que el que ha de ser reprimido" (Spinoza, 2011, p. 320). Por su parte Lukács en su afán por ver solo los aspectos marxistas de Hegel se ha olvidado o, 
mejor aún, ha subestimado el papel que la teología juega en la elaboración del sistema hegeliano. Recordemos lo que dice Ramón Valls en el libro de Fraijó "toda la filosofía de Hegel es filosofía de la religión" (Fraijó, 2010, p. 210).

Pero la historia está repleta de situaciones en las que los filósofos toman o ignoran de los demás solo lo que consideran importante para la elaboración de sus propios sistemas. Francisco José Martínez Martínez en su "Metafísica" nos recuerda el desvío del camino axiológico que tomaron unos jóvenes marxistas, se está refiriendo a Merleau-Ponty, Sartre y desde luego Lukács, ya que al parecer éstos optaron por la ontología de la praxis, quitándole de este modo peso a la supuesta primacía que, según ellos, le había dado Marx a la naturaleza sobre los valores sociales, lo que los llevó a caer en el llamado "idealismo de la praxis" (Martínez, 2011, p. 320). Desconociendo estos jóvenes marxistas que la primacía dada a la naturaleza es en primer lugar un hecho fáctico y primordial, solo por poner un ejemplo: sin ser natural no hay ser social, es inevitable que la primacía sea para la naturaleza, es en este sentido que hay que entender la ontología materialista. Estos aspectos son traídos a colación ya que se desarrollarán en el siguiente apartado, el del desarrollo posterior a Hegel de su herencia filosóficoreligiosa. El otro ejemplo lo aclara Reale y Antiseri, en su magnífica obra "Historia del Pensamiento Filosófico y Científico", se trata otra vez de lo mismo, o sea, cómo se fuerza una situación para acomodarla a nuestros intereses, cosa al parecer muy común en esto de la filosofía, esta vez es Hegel quien es acusado de forzar los sistemas filosóficos de sus contrincantes para que su propia teoría quedara bien posicionada, por eso es por lo que le otorga a Fichte y Schelling papeles específicos, pero solo buscando su propio interés (Reale, 2010, pp. 105 ss).

\section{Herederos del hegelianismo, hegelianos de izquierda y hegelianos de derecha}

Llegamos a la última parte del artículo, recordar que se trata de ver la recepción que tuvo el concepto de religión hegeliano y, esta recepción, presenta su máxima expresión en las voces de mayores representantes, esto es, los hegelianos de izquierda y los de derecha. Una vez desaparecido el gran maestro, sus discípulos se dieron a la tarea de continuar con el enfrentamiento que se venía dando entre la filosofía y la teología. Es así como de dicha disputa surgieron dos corrientes de pensamiento que pretendían, cada una por su lado, dar solución al problema. Recordando aquella ya clásica "Querelle des anciens et des modernes" que se había presentado anteriormente en torno al arte.

Estas dos corrientes estaban conformadas, en primer lugar, por los hegelianos de derechas o viejos hegelianos, integrada por Göschel y Corandi, los cuales pasaron a ser llamados la escolástica del hegelianismo, cuya mayor pretensión era hacer creer a todos los demás que Hegel era completamente compatible con 
el cristianismo. No olvidar que eso mismo fue lo que hicieron los padres de la iglesia católica con la obra de Platón y la escolástica con Aristóteles. En ambas ocasiones se pretendió unificar o acomodar un gran sistema filosófico al ya existente cristianismo; es así como el cristianismo ha alcanzado la altura que tiene, ya que fue un edificio construido con materiales tomados de los textos de los grandes filósofos de la humanidad. Basta con pensar en el uso que se hizo en Alejandría de los textos platónicos por parte de los padres de la iglesia: Clemente de Alejandría, Orígenes y Afrodísio de Alejandría; éstos, estudiando las traducciones provenientes de mundo árabe, tomaron "El Timeo" como modelo y elevaron a la altura de creador al Demiurgo platónico, aquél que en un principio había sido creado para que sirviera de enlace entre el mundo sensible material y el suprasensible ideal pasó a ocupar el lugar del gran creador del mundo.

En segundo lugar, están los hegelianos de izquierda, los cuales a su vez se dividen en dos grupos; los primeros son: Strauss, Stirner, Bauer y Ruge, estos autores reconocen la superioridad de la filosofía, pero el problema es que atacan la especulación hegeliana con más especulación: "Toda la crítica filosófica alemana desde Strauss hasta Stirner se limita a la crítica de las ideas religiosas" (Marx, 2010, p. 32). Estos autores no estaban en verdad tratando de derribar el edificio hegeliano sustentado en gran parte en la religión, para ellos: "El progreso consistía en incluir las ideas metafísicas, políticas, jurídicas, morales y otras, supuestamente dominantes, en la esfera de las ideas religiosas o teológicas" (32). Como se puede ver, esto los empujaba cada vez más hacia el idealismo hegeliano, el cual a su vez estaba atrapado en el supuesto kantiano de que el origen de todo nuestro conocimiento provenía de ese tronco común originario, de ese "Yo puro", del que provenían todas las categorías del conocimiento y que en síntesis es llamado a priori. Esta disputa trae como consecuencias que: "Los jóvenes hegelianos coinciden con los viejos hegelianos en la creencia en la dominación de la religión, de los conceptos, de lo universal, en el mundo existente. Solo que los unos combaten la dominación como usurpación, y los otros lo celebran como legítima" (Marx, 2010, p. 33).

La disputa en torno a la herencia hegeliana del concepto de religión y la confrontación surgida alrededor de sus receptores continúa dando frutos. Quizás el foco central consiste en que atacan ideas con ideas, con lo que en el fondo caen prisioneros del mismo sistema que pretenden destruir, ya que en lugar de acudir a los hechos reales de los que salen las confrontaciones, se quedan, digamos, encerrados en sus gabinetes pensando que los problemas ideológicos de la sociedad se resuelven desde el cómodo sillón, a la manera cartesiana, y así quedan atrapados en la esfera religiosa que creían superar. La crítica que hace Marx de estas posturas es que ninguno se ha parado a pensar de dónde provienen los problemas que estudian, de ahí que terminen comparando ideas con ideas, ninguno se ha atrevido a pensar que los fenómenos que estudian proceden de la realidad social en la que ellos mismos viven y que solo por la gran ceguera humana no han podido ser vistos hasta ahora. 
Antes de pasar a desarrollar los presupuestos de los hegelianos de izquierda, lo más aconsejable es ver algunos de los pensamientos previos a su génesis. Como se ha venido repitiendo de manera reiterada en el artículo, lo más apropiado es no dejar por fuera aspectos destacados que jugaron un papel central en la elaboración de estas hipótesis. Hay ocasiones en las que los grandes pensadores se ven en la necesidad de, o bien obviar aspectos de sus predecesores o bien resaltarlos. De ahí la queja antes expuesta en la que Garaudy se refiere a los aspectos dialécticos que resalta Lukács en Hegel, pero a costa de opacar los teológicos, siendo estos últimos más importantes que los primeros, al menos para Lukács. Éstos supuestos lo que indican es que en muchas ocasiones hacemos lecturas que están desviadas de las verdaderas intenciones de sus autores, y aunque Lukács recibe dos amonestaciones, como se indicó antes, no por eso dejan de ser valiosas las cosas que nos tiene que decir. Estos comentarios de Lukács relacionados con Hegel tienen que ver con que Lukács ve en él al precursor de todo el marxismo y, por eso, se le hace tan difícil ver cómo Hegel se extravía por los senderos de la religión, llegando ésta a convertirse en el centro de toda su filosofía. El motivo de la centralidad de la religión en la filosofía hegeliana ya ha sido descrito en diferentes partes de este artículo, pero ante la importancia del mismo se hace necesario estar dando continuamente referencias al mismo. Para poner un ejemplo más, miremos lo que al respecto dice Nicolai Hartmann "Es preciso tener presente que la filosofía de Hegel, al ser eminentemente una filosofía de lo Absoluto, toda ella podría ser denominada Filosofía de la religión en sentido amplio" (Hegel, 1981, p. 8).

Todos estos preámbulos introducidos en torno al pensamiento de Hegel, los cuales nos indican que la obra de éste gira en torno a la teología, no privó al propio Hegel de proponer que, debido a tanto cansancio producido por la especulación alrededor de la figura de Dios, nos deberíamos fijar también en la olvidada figura del Hombre. Feuerbach se tomó tan al pie de la letra la propuesta de su maestro que se quedó solo con el hombre. Así llegamos al discípulo más aventajado de Hegel relacionado con los aspectos teológicos: Feuerbach, quien a su vez abandonó la teología, ya que él no quería creer sino pensar, y por eso se decantó por la filosofía. Es en este grupo de los hegelianos de izquierda en donde se da solución a la confrontación. Hay que decir que es un grupo reducido, ya que solo está compuesto por dos figuras: Feuerbach y Marx. Como veremos a continuación, Feuerbach, aún dentro de su grandeza, no logra tampoco romper con la visión cerrada de las anteriores concepciones, y esta vez no es por que quede atrapado en los fuertes lazos de la religión, sino porque no sabe salir del materialismo mecanicista. Esto lo pone de manifiesto Marx en "La ideología alemana" cuando afirma: "Feuerbach quiere es establecer la conciencia del hecho histórico, quiere crear, como los demás teóricos, una conciencia exacta acerca de un hecho existente, mientras que de lo que se trata es de revolucionar lo existente" (Marx, 2010, p. 88). De ahí que Feuerbach no sea capaz de ver, que de lo que se trata no es de repetir teóricamente los mantras que se han venido repitiendo en 
la historia, sino que de lo que se trata es de revolucionar esa existencia estática, que lo ve todo como inamovible, o lo que es peor, ver la realidad como eterna y al hombre como incapaz para modificarla. Por eso es por lo que Feuerbach:

No ve que el mundo sensible que lo rodea no es una cosa dada directamente desde la eternidad y siempre igual a sí misma. Sino el producto de la industria y de las condiciones sociales, es decir, en el sentido de que es un producto histórico, el resultado de la actividad de toda una serie de generaciones (Marx, 2010, pp. 90-91).

Es este uno de los motivos por los que la humanidad está en eterna deuda con Marx, ya que es debido a su gran capacidad intelectual que el hombre pudo salir de la oscuridad en la que llevaba sumido desde los tiempos en los que se le venía otorgando, no solo la autoría, sino también la primacía de todo lo que ocurría a fenómenos supra-terrenales. Así lo deja de manifiesto Moses Hess en los "Manuscritos de economía y filosofía". "Veo en él... [En Marx] a Rousseau, Voltaire, Holbach, Lessing, Hegel y Heine fundidos en una sola persona" (Marx, 2001 p. 224). A este respecto están también estas otras palabras:

Solo él era un genio, nosotros, a lo sumo, fuimos talentos. (Engels). El genio es el genio, es algo que no se explica, ciertamente, que a lo sumo se constata. Que tal genio sea, además, filosófico se explica, ciertamente, por la encarnizada labor de estudio de la historia de la filosofía que llevó a cabo a lo largo de años, de Epicuro a Hegel, pasando por Kant, Rousseau, para finalizar en Feuerbach (Althusser, 2002, p. 13).

Es con Marx con el que la humanidad sale del marasmo y conquista el esquivo mundo material, que ante los ojos de casi toda la historia de la filosofía estaba en manos de poderes ajenos a los humanos. Será solo con Marx con el que la humanidad despierte del sueño metafísico en el que andaba transitando desde los albores de su génesis. Marx desvelará los grandes secretos que siempre han estado guardados, descubriendo, no solo el secreto de Hegel, sino también en de los hegelianos de derecha, el de los hegelianos de izquierda, y hasta el de su más próximo predecesor, del que entre otras cosas sentía gran admiración y respeto: Feuerbach.

Así Althusser lo interprete de otra manera: "Marx retomó de Hegel la idea de la dialéctica, pero no se limitó a "darle la vuelta" para liberarla de la pretensión o del fantasma idealista de la autoproducción, sino que la transformó hasta convertirla el algo distinto" (Althusser, 2002, p. 77). Los presupuestos ya están confirmados, la dialéctica hegeliana ha adquirido su real desarrollo al ser puesta del revés por Marx. Teniendo todos estos datos en cuenta Lukács emprende la tarea de continuar con el desarrollo de la crítica a la vieja teología hegeliana, para eso veamos los aportes que realiza tomando referencias de Goethe. "El que tenga ciencia y arte tiene también religión; el que no posea ninguna, que tenga 
una religión" (Lukács, 1967, p. 576). Aquí sí vemos la dimensión de lo religioso en toda su magnitud, es tan grande el poder de la religión como concepción del mundo, que para Goethe es no solo el arte sino la misma ciencia, de ahí que el que no posea ninguna de las dos inevitablemente tiene que tener una religión. Lukács continúa diciendo que "Hegel considera el arte como parte de la evolución religiosa, como transición entre la pura religión natural y la religión revelada, el cristianismo" (Lukács, 1966, p. 130). Tenemos que hacer justicia a esta posición que se lo juega todo a la única carta posible de jugar en el ámbito histórico, es así como no podemos poner en duda la relación que encuentra Lukács entre los principios que defiende Hegel y la situación de la filosofía alemana en aquella época, la cual Lukács tilda de «atrasada» (130). Y así se logra una lectura desde luego más próxima a la realidad que un simple análisis de la obra de Hegel.

Este es el gran logro del materialismo tanto histórico como dialéctico: ver los hechos siempre desde sus connotaciones sociales y desde las interacciones entre los individuos con su respectiva realidad socio-económica. "Toda actividad del hombre y cada una de sus recepciones de fenómenos tiene lugar en un contexto social y está por tanto objetivamente vinculada con el destino de la especie, con la evolución de la humanidad, sea esa vinculación directa o indirectamente, próxima o mediada" (Lukács, 1967, p. 474), la cual habla de los logros que una sociedad tiene en todos los ámbitos de su producción; y como no puede ser de otro modo, desde luego que los ámbitos que estamos tratando aquí son fruto del hombre en esa interacción con la realidad. Marx lo deja suficientemente claro:

Las ideas de la clase dominante son, en cada época, las ideas dominantes, es decir, la clase que es el poder material dominante de la sociedad es, a la vez, su poder inmaterial dominante. La clase que dispone de los medios para la producción material dispone con eso, a la vez, de los medios para la producción intelectual, de manera que con eso, a la vez, las ideas de aquellos a quienes les faltan los medios para la producción intelectual están sometidas, por término medio, a esa clase (Marx, 2010, p. 98).

\section{Conclusión}

Hemos realizado un amplio recorrido por las más destacadas recepciones llevadas a cabo en la historia de las nociones de la religión de Hegel, las hemos confrontado con los más grandes pensadores que le han dedicado gran parte de sus especulaciones filosóficas. También hemos visto la confrontación surgida entre los propios herederos del pensamiento hegeliano. Se ha visto con claridad la lucha que mantuvo Hegel con la filosofía ilustrada, en la que él abogó por la defensa de la religión. Quizás el aspecto más destacado del articulo sea la relación que hay entre la religión y la política, en este sentido es de radical importancia ver que esa conexión que encontró Hegel sigue aún vigente en gran parte del mundo, por no decir que en gran parte del planeta existen aún teocracias, en donde la religión 
es la que tiene la última palabra en todo lo relacionado con el ámbito social. Más paradójica resulta esta relación en los países occidentales desarrollados y altamente civilizados, como lo es el caso de los Estados Unidos de Norte América, en donde aún se llevan a cabo luchas en torno al darwinismo y al creacionismo. Ni que decir de los países hispánicos, en donde la religión en alianza con la política se ha puesto de acuerdo para legitimarse cada uno a su manera en el poder.

También a modo de conclusión sería bueno decir que, si para Hegel la religión es un sentimiento superior al que deberíamos todos plegarnos, también lo es el hecho del que nos habla Lukács al invitarnos a superarlo y dejar que sean las propias producciones humanas las que tomen el relevo a esta poderosa manera de ver la realidad. Para Lukács es tan grande el poder del sentimiento religioso que, solo extinguiéndose como sentido del mundo, podría convertirse en autentico sentido cismundano para el mismo. "La necesidad religiosa no puede extinguirse más que cuando el hombre consiga convertir en elementos con sentido de una vida cismundana con sentido, todas las energías espirituales y anímicas que hasta ahora no han podido vivirse más que de firma religiosa" (Lukács, 1967, p. 576).

Y efectivamente es así, solo hasta que consigamos convertir todas las energías que hemos depositado en forma religiosa, convertir digo, en energías del mundo corriente, del mundo cismundano, podremos decir que habremos extinguido la necesidad religiosa. En el momento que el hombre proyecte sobre el suelo real que pisa las proyecciones que viene realizando idealmente en un mundo inexistente conseguirá apropiarse la realidad social que siempre le han resultado esquivas, porque ya es hora de que el hombre consiga la dignidad de su grandeza y dejar de depositarla en esferas supra terrenales, a las que ha acudido huyendo de una realidad ante la cual siempre se ha sentido aplastado y, que el sentimiento religioso, en lugar de ayudar a llevar ha contribuido en parte a hacer más pesado, pasando así a formar parte de una carga que cada vez se hace más necesario descargar $\varphi$

\section{Referencias}

Althusser, L. (2002). Para un materialismo aleatorio. Madrid: Arena libros.

Francis, F. (1988). El fin de la historia. Chicago: Artículo.

Fraijó, M. (2010). Filosofía de la religión. Madrid: Trotta.

Garaudy, R. (1973). Dios ha muerto: un estudio sobre Hegel. Buenos Aires: Siglo XXI.

Garaudy, R. (1985). El método de Hegel. Buenos Aires: Leviatán. 
Hegel, G, W, F. (1981). El concepto de religión. México, D.F: Fondo de Cultura Económica.

Hegel, G, W, F. (2003). Escritos de juventud. México, D. F: Fondo de Cultura Económica.

Hegel, G, W, F. (2006). Fenomenología del espíritu. Valencia: PRE-TEXTOS.

Hegel, G, W, F. (2010). Fenomenología del espíritu. Madrid: Abada.

Lukács, G. (1964). El joven Hegel. Barcelona: Grijalbo.

Lukács, G. (1966). Aportaciones a la historia de la estética. México: Grijalbo.

Lukács, G. (1967). Estética. Barcelona: Grijalbo.

Martínez, M, F, J. (2011). Metafísica. Madrid: UNED.

Marx, K. (2001). Manuscritos del 44. Madrid: Alianza.

Marx, K. (2010). La ideología alemana. Buenos Aires: Losada.

Reale, G. y Antiseri, D. (2010). Historia del pensamiento filosófico y científico. Barcelona: Herder.

Román, M. T. (2008). Sabidurías orientales de la antigüedad. Madrid: Alianza.

Solís, C. y Sellés, M. (2009). Historia de la ciencia. Madrid: Espasa Calpe.

Spinoza, B. (2011). Ética. Madrid: Alianza. 